\title{
ROLLING AND RECRYSTALLIZATION TEXTURES OF BCC STEELS
}

\author{
K. Lücke*, M. Hölscher* \\ Institut für Metallkunde und Metallphysik, RWTH Aachen, \\ Kopernikusstr. 14, D-5100 Aachen, FRG \\ - Stahlwerke Peine Salzgitter AG, Postfach 411180, \\ D-3320 Salzgitter, FRG
}

\section{INTRODUCTION}

The rolling and recrystallization textures of the different types of bcc steels often show great similarities, but also exhibit characteristic differences which e.g. depend upon starting texture, microstructure and condition of precipitations. In this paper this behaviour will be discussed for three examples belonging to three entirely different types of steels with very different requirements for technical properties:

(1) Deep drawing steels (e.g. low carbon steel). Here the most important property is a good deformability in deep drawing. This behavior is favoured by a texture formed in such a way that during deep drawing the material flow occurs from the width and not from the thickness of the sheet and that it is equal for different directions in the sheet plane, i.e. by materials with a high $r$-value and a low $\Delta$-value ( $r$ is the Lankfort parameter). Both properties can be achieved by a texture which after recrystallization consists of a homogeneous strong fibre texture with a $\{111\}$ plane parallel to the sheet plane.

(2) Ferritic stainless steels (e.g. Fe16\%Cr) Here again the described requirements for deep drawability should be fulfilled,but additionally also the ridging often occuring in $\mathrm{Cr}$ - steels should be suppressed. This again means a $\{111\}$ fibre texture but also a topologically random arrangement of crystallites should be achieved ${ }^{1}$.

(3) Electrical steels (e.g. Fe3\%Si). For the use of these steels in transformers high magnetic permeability for magnetisation in rolling direction is required which can be obtained by having a $\langle 100\rangle$ direction parallel to the rolling direction. Technologically this can be achieved by forming a very sharp Goss texture $\{011\}<100>$ by secondary recrystallization.

As will be shown the differences in the rolling and recrystallization textures of these various steels largely originate from differences in microstructure and texture of the hot rolled band.

\section{DESCRIPTION OF BCC TEXTURES}

For demonstrating textures in bcc metals mostly $\{110\}$ pole figures are measured because they yield the highest X-ray intensity. Although being commonly used such pole figures impose large difficulties on the quantitative inter- 

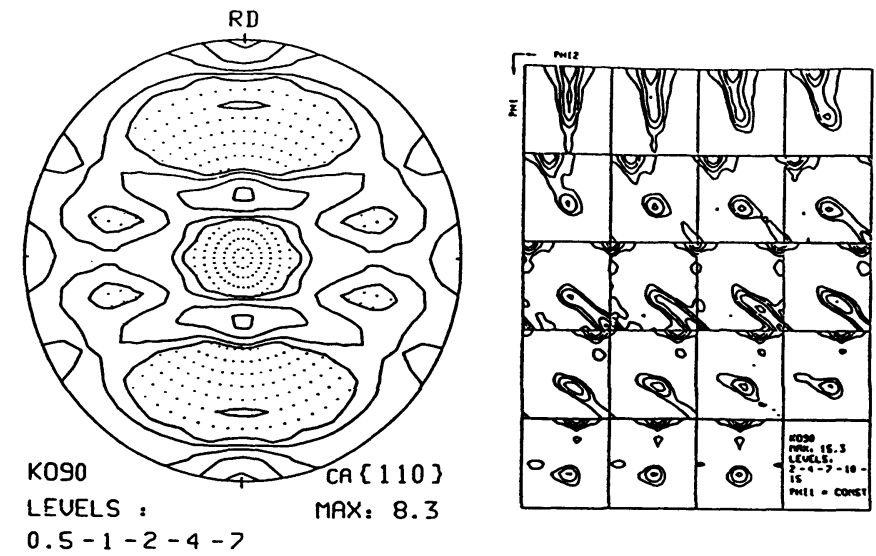

Fig 1 : Rolling texture of a bcc steel (90 \& CR)

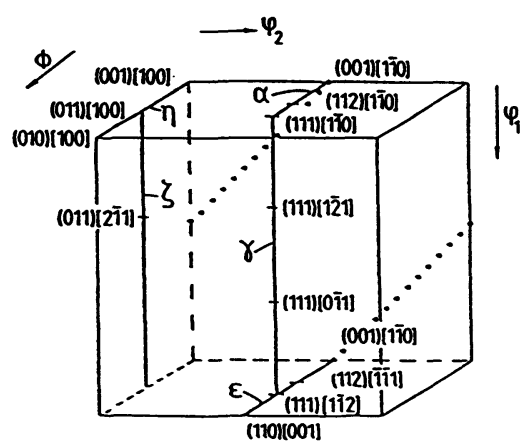

Fig 2 : Reduced euler space with fibres

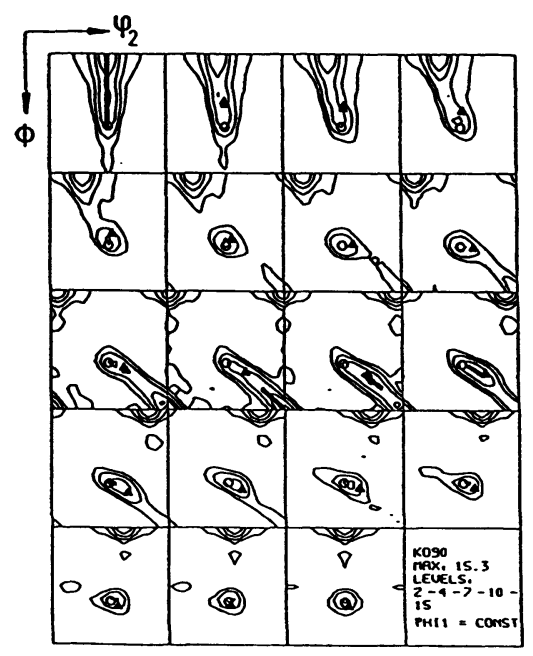

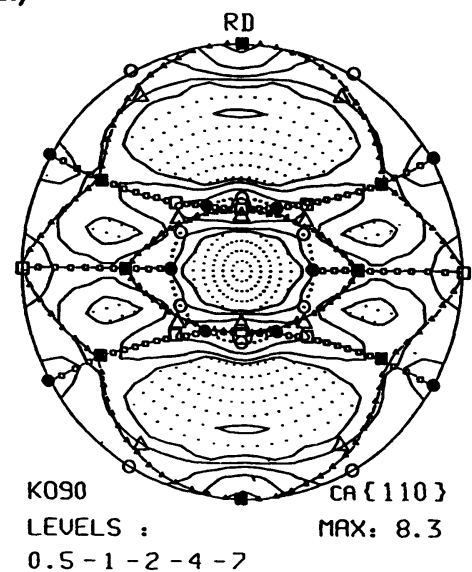

Fig 3 :

Fibres in a polfigure

$\alpha: \square$

$\gamma: 0$

Fig 4 : Fibres in the euler space 
pretation of textures, since the superposition of the considered types of poles (e.g. $\{110\}$ poles) stemming from different orientations leads to a high degree of ambiguity. For obtaining a less ambigous description the orientation distribution funkction (ODF) must be calculated. It is mostly presented in the three dimensional orientation space in which an orientation $g$ is given by the three eulerian angles $\varphi_{1}, \Phi$ and $\varphi_{2}$. In the present paper the ODF is reproduced from 3 to 4 different pole figures $(110,200,112,103)$ by the series expansion method $\left(l_{\max }\right.$ $=22$ ) and is represented in form of contour line plots in the sections $\varphi_{1}$ $=0^{\circ}, 5^{\circ}, . ., 90^{\circ}$ through the eulerian space ${ }^{2}$ (Fig.1).

The rolling and recrystallization ODFs of boc steels are mostly composed of certain orientation fibres and their main features can thus be represented in a very condensed manner by plotting the orientation density along these fibres $3,4,5$. The most important of these fibres appear as straight lines in the Euler angle space and are shown in Fig.2:

$$
\begin{aligned}
& \alpha \text {-fibre }<110>\| R D \\
& \gamma \text {-fibre }\{111\} \| N D \\
& \eta \text {-fibre }<001>\| \text { RD }
\end{aligned}
$$$$
\left\{\begin{array}{l}
001\}<110>\text { to }\{111\}<110> \\
111\}<110>\text { to }\{111\}<112> \\
001\}<001>\text { to }\{011\}<110>
\end{array}\right.
$$

\section{MODEL CALCULATIONS OF BCC ROLLING TEXTURES}

For the description of the rolling textures of BCC steels both experimental results as well as Taylor model calculations suggested the use of the $\alpha$-fibre. The use of the $\gamma$-fibre, however, was controversial for some time since there also another fibre, the so-called $\beta$-fibre, was discussed. This fibre was a result of first calculations of texture development according to the Taylor full constraints model of polycrystalline deformation which, additionally to the $\alpha$-fibre, predicted a fibre running from $\{112\}<110\rangle$ to about $\{11118\}<4411\rangle$. The decision whether the $\gamma$ - or $\beta$-fibre would be the physically more reasonable one was not possible by using pole figures only. Fig. 3 shows that both combinations, $\alpha$ and $\gamma$ or $\alpha$ and $\beta$, are able to describe the pole figures of the rolling texture shown in Fig.1, but the ODF representation of Fig. 4 exhibits the better fit of the combination $\alpha$-and $\gamma$-fibre. Although these differences appear to be small theyx are strictly reproducible and of great importance for the interpretation of the deformation modes.

The reason for the deviation from the original Taylor model is connected with the grain shape. The original "full constraints" Taylor model allows plane strain for the various grains only of the size of the macroscopic strain of the specimen ${ }^{6,7}$. The ODFs resulting from this model for different strains are shown in the first line of Fig.5. In this figure sections $\varphi_{2}=45^{\circ}$ of the ODFs are chosen since they happen to contain both the $\alpha$ - and $\gamma$-fibre (see Fig.2). The orientations of the $\beta$-fibre $\{112\}<110\rangle$ and $\{11114\}<4411>$ (6 $6^{\circ}$ below $\{111\}<112\rangle$ at $\varphi_{1}=90^{\circ}$ ) are clearly preferred. But during rolling the initially more or less equiaxed grains become flat which allows a shear $\varepsilon_{13}$ parallel to the sheet plane in rolling direction, since for such band shaped grains the incompatible deformation between neighbouring grains due to the $\varepsilon_{13}$ shear then appears only at their smallest edge and thus may only influence a small seam of the grains. This relaxed constraints model which additionally to plane strain also allows the shear $\varepsilon_{13}$ is called lath model. In the texture simulations for this case the main orientation is shifted to the exact position of $\{111\}<112\rangle$ on the $\gamma$ fibre as to be seen in Fig.5. After further deformation and flattening of the grains also the shear $\varepsilon_{23}$ becomes possible without compatibility problems which 

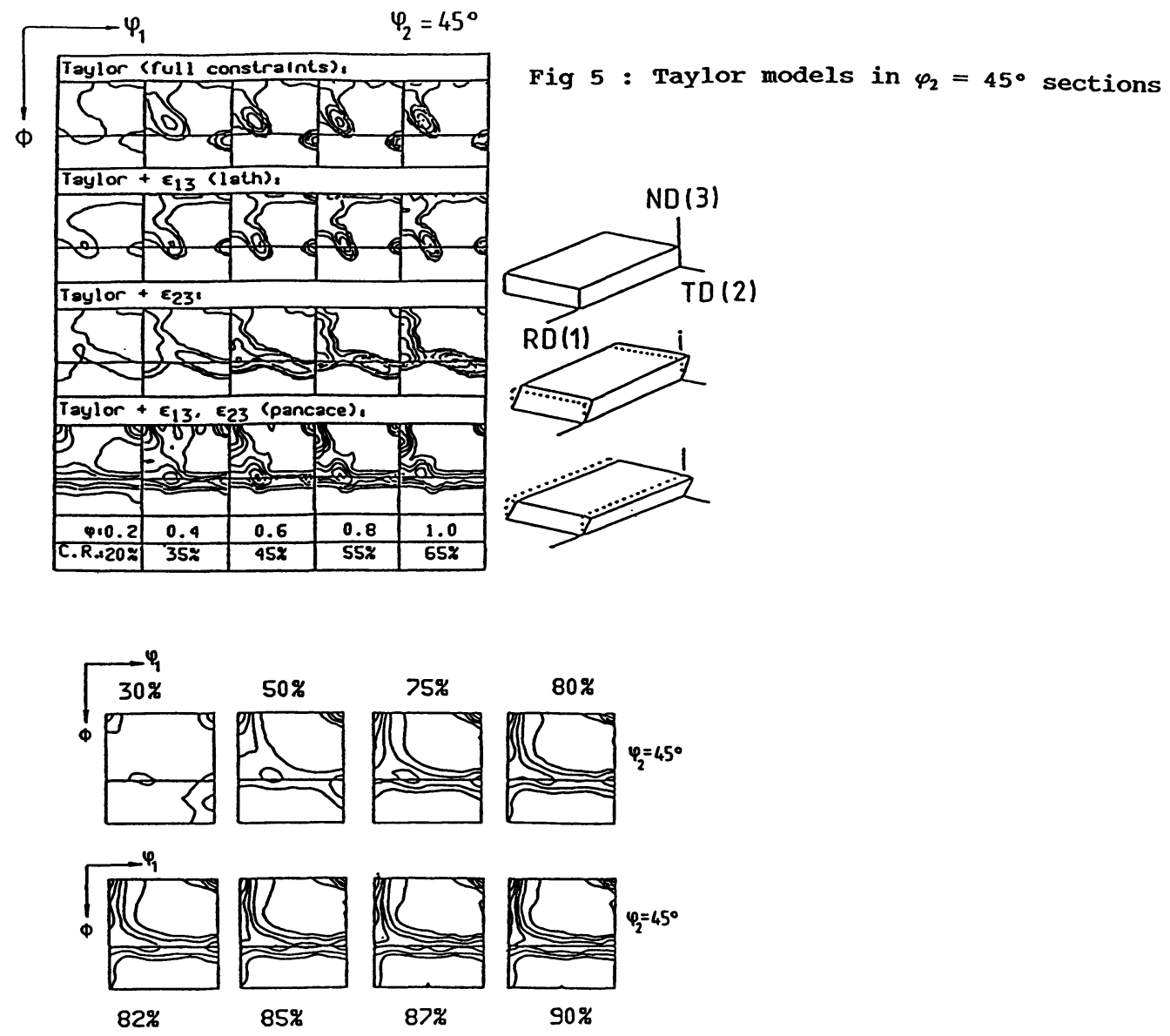

Fig 6 : Experimental datas of the cold rolling development in $\varphi_{2}=45^{\circ}$ sections

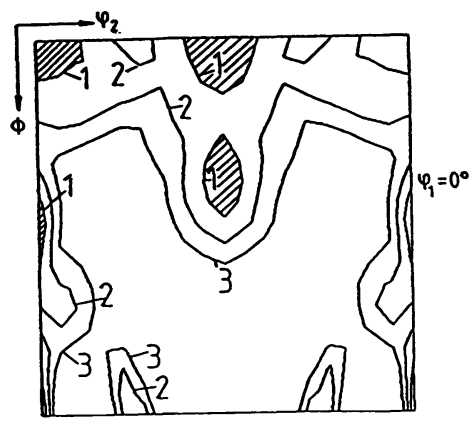

Fig 7 : Rotation velocities in $\varphi_{1}=0^{\circ}$ section 
would lead to the texture shown in the third line of Fig.5. Finally, simultaneous relaxation of both shears lead to a texture as shown in the last line of Fig.5. This so-called pancake model gives a quite homogeneous orientation density along the $\boldsymbol{\gamma}$-fibre ${ }^{8,9}$.

In carrying out model calculations an often neglected parameter is the starting texture. The calculations of Fig.5 started with a random orientation distribution, but the texture development in materials with a strong starting texture may be quite different. Here it is useful to consider the rate of rotation of the various orientations of the grains during rolling deformation. As an example in Fig.7 the angle calculated by the Taylor full constraints model for a rolling reduction of $10 \%$ is plotted for the section $\varphi_{1}=0$. The very slowly rotating regions are hashed. Although here $\left.\left\{\begin{array}{lll}11 & 11 & 8\end{array}\right\}<4411\right\}$ is the only stable end orientation, the two orientations $\{112\}<110>$ and $\{001\}<110>$ do nearly not rotate at all, i.e. they are metastable. All orientations which first rotate towards one of these two positions will there be fixed.

\section{EXPERIMENTAL INVESTIGATIONS OF ROLLING TEXTURE DEVELOP- MENT}

In Fig. 6 the transition from the Taylor full constraints model to the pancake model in which all shears parallel to the rolling plane are relaxed in the course of rolling is shown for an experimental example (Fe16\% Cr). There one sees that with increasing degree of rolling the orientation of the main component at $\{11118\}<4411>$ is shifted to $\{111\}<112>$ This transition is characteristic for all steels investigated. The main reason for the differences in the texture development of the here considered three types of steels lies in the hot rolling textures which act as starting textures and largely differ for cold rolling after the hot rolling textures due to different chemical compositions and pretreatments. Hot rolling of the low carbon steel takes place completely in the austenitic range. The subsequent transformation during cooling to ferrite results in a nearly random texture (Figs.8a,9). In the two alloyed steels $\mathrm{Fe} 16 \% \mathrm{Cr}$ and $\mathrm{Fe} 3 \% \mathrm{Si}$, in contrast, the ferrite is stabilized up to the hot rolling temperatures so that, since dynamic recovery during hot rolling prevents recrystallization, the deformation texture is present in the hot rolled material essentially contains the cold deformation textures (e.g. Fe16\% Cr, Figs.8b,10). Due to the rolling conditions the ranges near the surface are deformed by shear and those near the center by nearly plane strain. The shear texture of the surface consists of a strong Goss texture $\{011\}<100\rangle$ and of approximately $\{112\}<111\rangle$. The texture in the center is similar to a cold rolling texture with a strong $\alpha$-fibre, especially $\{001\}<110>$, and a $\gamma$-fibre ${ }^{10.11}$.

Concerning the development of the cold rolling texture (Fig.11), the low carbon steel exhibits a good agreement with the model calculations. The $\alpha$-fibre increases continuously and in the $\gamma$-fibre $\{111\}<112>$ is dominant up to a rolling degree of $70 \%$ (lath model,shear $\varepsilon_{13}$ ) and $\{111\}<110>$ for higher rolling degrees (pancake model, additionally shear $\varepsilon_{23}$ ). In the deformation range between $70 \%$ and $80 \%$ strong shear band formation takes place in the $\{111\}<112>$ grains which is probably responsible for the relatively weak increase of texture sharpness.

Despite of the quite different starting conditions the cold rolling textures of the alloyed steels show a rather similar development. At the surface (Fig.12a) again first $\{111\}<112>$ and then, after $75 \%,\{111\}<110>$ increases. The 


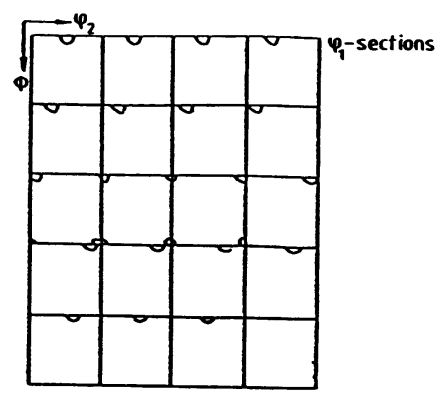

Fig 8a : Hot rolling texture low carbon steel
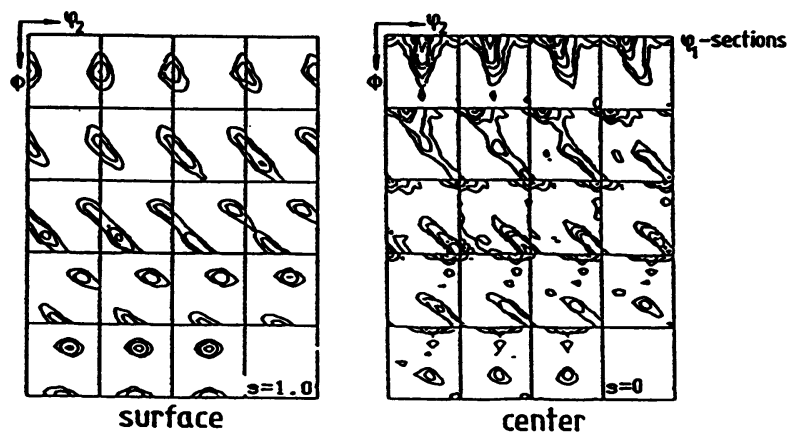

Fig 8b : Surface and center texture of Fe - $16 \% \mathrm{Cr}$ steel

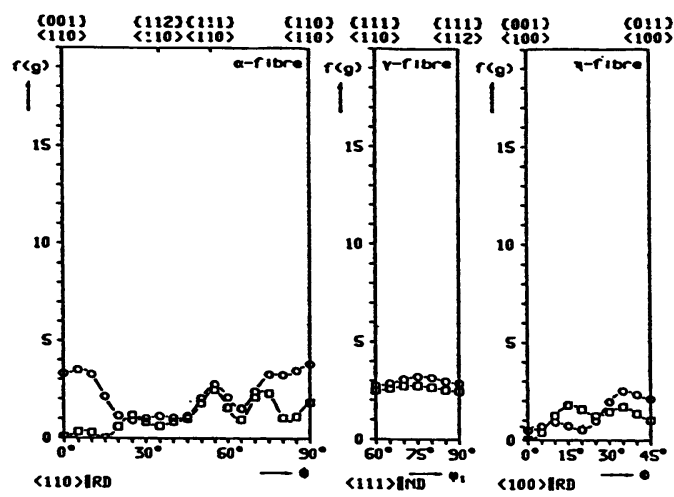
oup $\mathbf{s = c}$

Fig 9 :

hot rolling texture low carbon steel

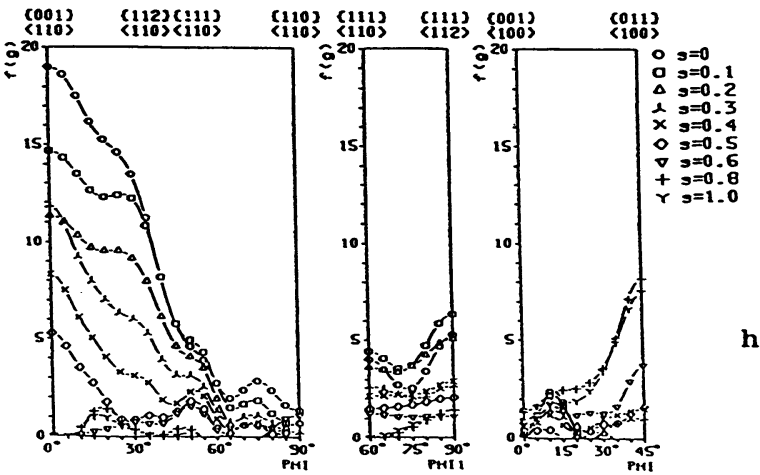

Fig 10 :

hot rolling texture Fe $16 \% \mathrm{Cr}$ 


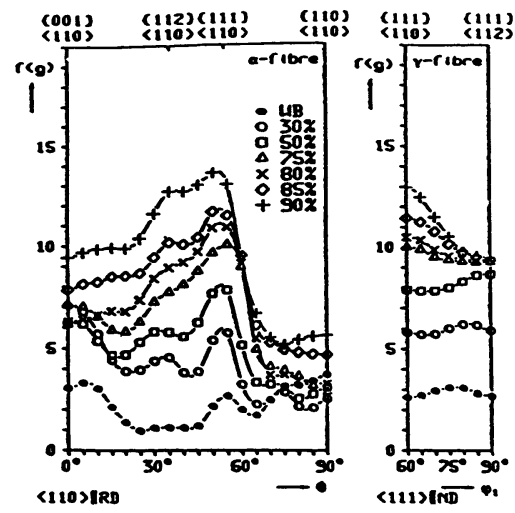

Fig 11 : cold rolling texture low carbon steel, c in solution

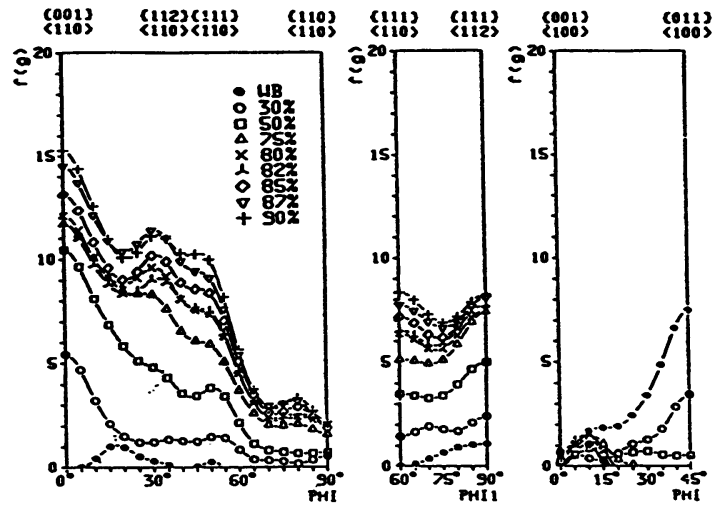

Fig 12a : Cold rolling texture $\mathrm{Fe} \mathrm{Cr} / \mathrm{Fe} \mathrm{Si}$ surface

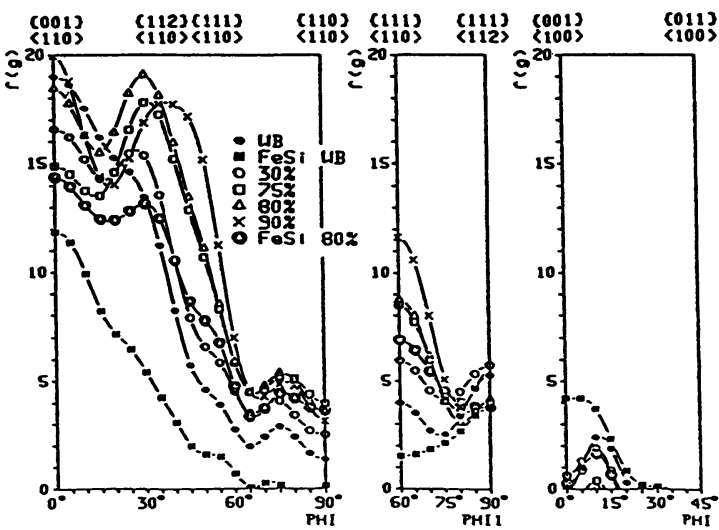

Fig 12b : Cold rolling texture $\mathrm{Fe} \mathrm{Cr} / \mathrm{Fe} \mathrm{Si} \mathrm{center}$ 


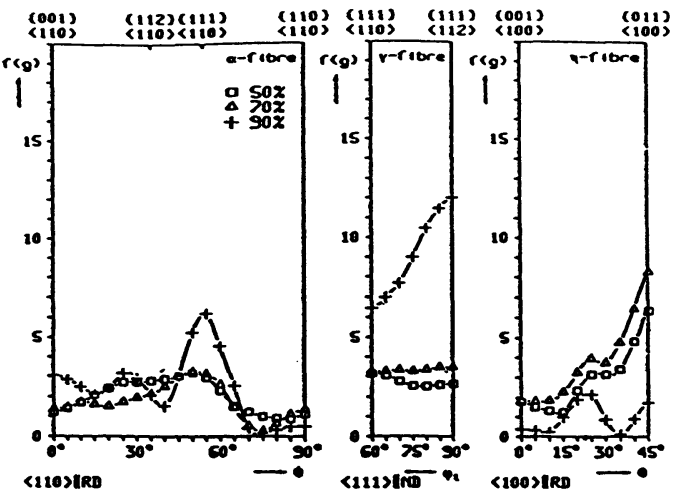

Fig 13a : Recrystallization texture low carbon steel, $c$ in solution

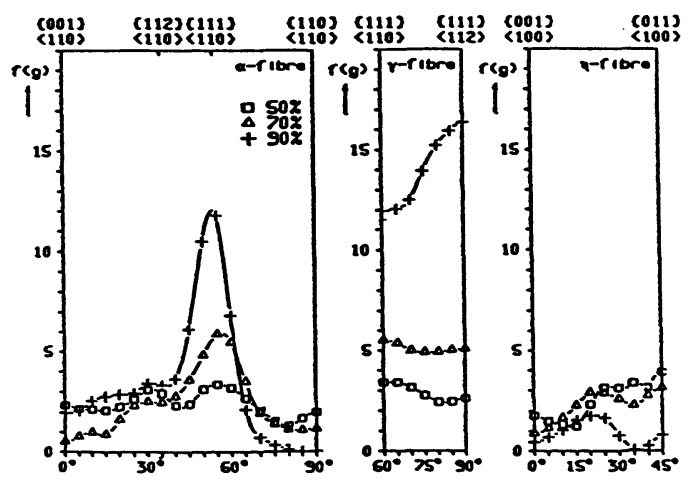
Fig 13b : $\begin{aligned} & \text { Recrystallization texture low carbon steel, } c \text { in } \\ & \text { precipitation }\end{aligned}$

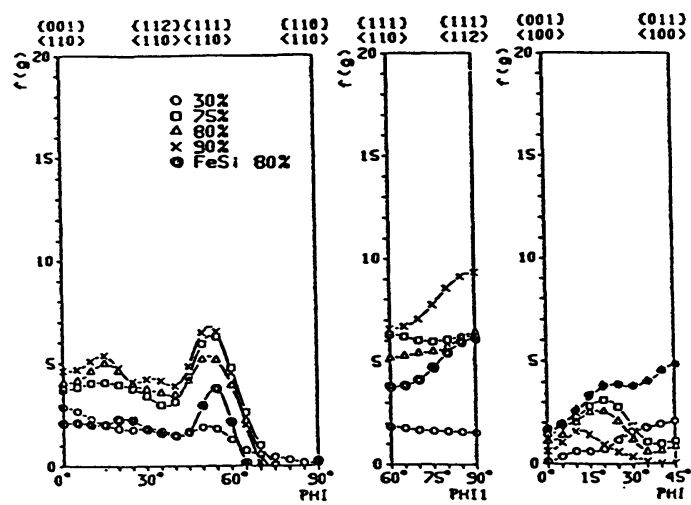

Fig 14a : Recrystallization texture $\mathrm{Fe} \mathrm{Cr} / \mathrm{Fe} \mathrm{Si}$ surface 
strongest difference is observed for the orientation density at $\{001\}<110>$ which is here much sharper and stronger than for the low carbon steels. The reason is that the strong shear orientation $\{112\}<111>$ not present in the low carbon steels rotates around the transverse direction into $\{001\}<110\rangle$ which is a rather stable orientation. The starting texture for the center is nearly a cold rolling texture and microstructure with elongated flat grains. This means that the pancake model is valid for the texture development already from the beginning of cold rolling and from the beginning $\{111\}<110>$ the most important orientation of the $\gamma$-fibre (Fig.12b). The relaxed constraints models are thus able to rather well describe the texture development of quite different steels.

\section{RECRYSTALLIZATION TEXTURES}

The recrystallization textures of the low carbon steel (see Fig.13) exhibits the most characteristic feature of the development of recrystallization textures being generally valid for ferritic steels: The orientation density of the $\alpha$ fibre, in particular of the strong rolling texture component $\{112\}<110>$ decreases nearly to unity. This can be seen by comparison with Fig.11, and only the orientation $\{111\}<110>$ simultaneously belonging to the $\alpha$-and $\gamma$-fibre remains rather strong after recrystallization.

As to be seen in Fig.14 for low degrees of rolling the recrystallization randomizes the whole texture. With increasing degree of rolling, annealing leads to growth of the orientations of the $\eta$-fibre, especially of the Goss orientation $\{011\}<100>$. High rolling degrees, finally, strengthen the $\gamma$-fibre and diminish the $\eta$-fibre. Both kinds of recrystallization texture development may be understood by combination of oriented growth and oriented nucleation. An example of oriented nucleation is demonstrated in Fig.15a where, as checked by TEM analysis, the $\gamma$-fibre grains appear to be hashed and the $\alpha$-fibre grains to be bright. After 10s annealing strong nucleation took place, but only in the striped grains i.e. in the $\gamma$-fibre, whereas no nuclei could be found in $\alpha$-fibre grains. Since at this stage the $\gamma$-fibre orientations still show the same intensity as the rolled material, it must be concluded that also the microscopically visible nuclei posses the same $\gamma$ orientations as the cold rolled material (see Fig.15b). No nuclei appear in the $\alpha$ oriented grains. The recrystallization of the $\alpha$-grains occurs by an oriented growth mechanism. Between the $\alpha$-orientation $\{011\}<211\rangle$ and the rolling texture component $\{111\}<112>$ one has an orientation relationship of $35^{\circ}$ around the $\langle 110\rangle$ transverse direction. This is close to the ideal orientation relationship of $27^{\circ}<110>$ found for high growth rates found in the bicrystal experiments by Ibe and Lücke $e^{12}$ and allows growth of of the $\gamma$-fibre nuclei into the $\alpha$-fibre grains as also can be observed directly in the microscope. Nearly the same fast growth relationship exists between Goss and and the rolling component $\{111\}<112>$. This principally explains the occurance of the goss component in the recrystallizationstexture. Its nucleation is assumed to take place in shear bands, rotated $35^{\circ}$ around the transverse direction. The amount of goss increases with deformation since the $\{111\}<112>$ component and the shear banding in this component increase. For medium rolling degrees (about $70 \%$ ), where the change of the rolling texture development (lath to pancake model) was found to take place, the development of $\{111\}<112>$ stops and, moreover, the shear bands rotate into rolling direction, so that the amount of Goss even decreases again.

This interpretation is supported by the fact that a high amount of carbon in solution (Fig.13a) enhances the formation of Goss orientation, whereas in the 


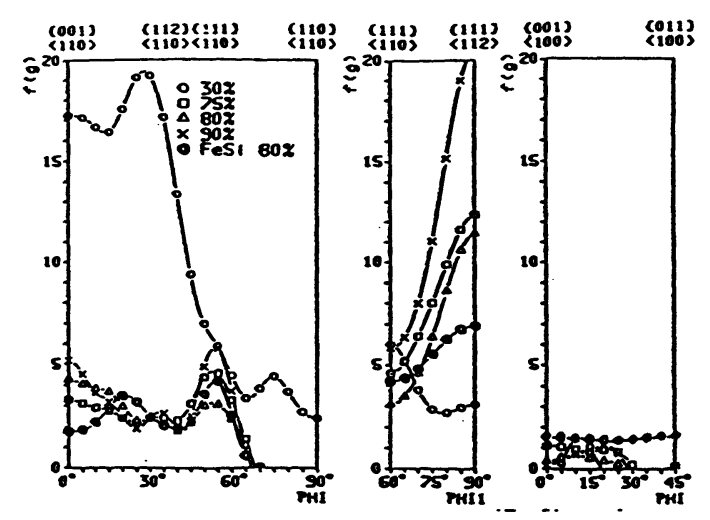

Fig 14b : Recrystallization texture Fe Cr / Fe Si center

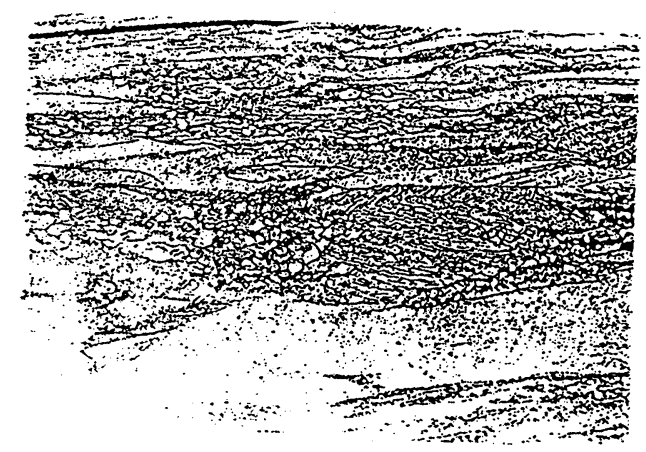

Fig 15a : Cold rolled and $10 \mathrm{~s}$ annealed at $700^{\circ} \mathrm{C}$

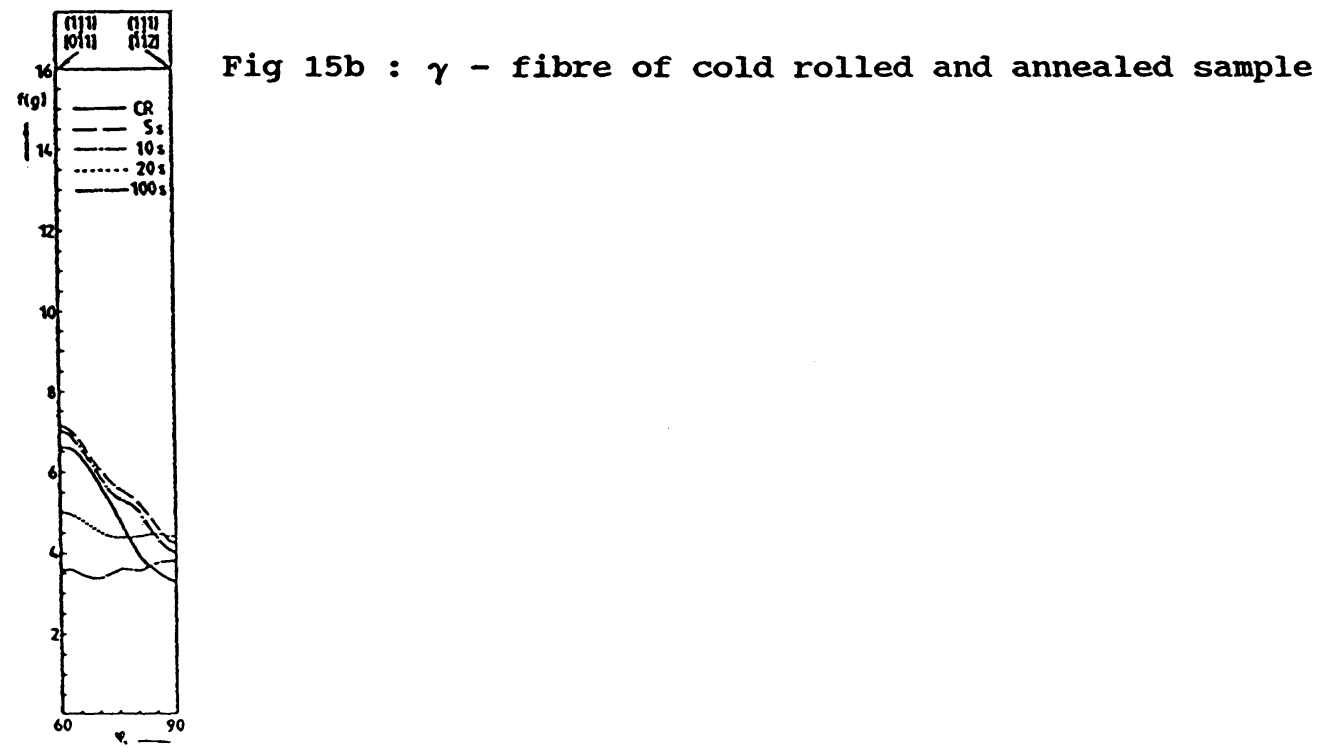


Tab.1: Textural requirements for various steels

\begin{tabular}{|c|c|c|}
\hline STEEL & $\begin{array}{l}\text { DESIRED PROPER- } \\
\text { TIES }\end{array}$ & REQUIRED TEXTURE \\
\hline $\begin{array}{l}\text { (1) Doep drawing stoels } \\
\text { (low carbon) }\end{array}$ & $\begin{array}{l}\text { Good deformability } \\
\text { High r-value } \\
\text { (Lankford parameter) } \\
\text { Isotropic deformation } \\
\text { low } \Delta r \text {-value } \\
\end{array}$ & $\begin{array}{l}\text { \{111\} Fibre texture } \\
\text { with parallel } \\
\text { normal direction }\end{array}$ \\
\hline $\begin{array}{l}\text { (2) Fenritic stainless } \\
\text { steels } \\
\text { (c.g. Fe16\%Cr) }\end{array}$ & $\begin{array}{l}\text { Good deformability } \\
\text { as in (1) } \\
\text { Avoiding of ridging } \\
\text { and raping }\end{array}$ & $\begin{array}{l}\text { \{111\} paralled } \\
\text { normal direction } \\
\text { Topologically random } \\
\text { distribution of grains }\end{array}$ \\
\hline $\begin{array}{l}\text { (3) Bloctrical stoels } \\
\text { (c.g. Fe3\%Si) }\end{array}$ & $\begin{array}{l}\text { Low magnetic losses } \\
\text { High permeability } \\
\text { in rolling direction }\end{array}$ & $\begin{array}{l}<100>\text { parallel } \\
\text { rolling direction } \\
(\text { e.g. Goss-texture } \\
\text { 011 }\}<100>\text { ) }\end{array}$ \\
\hline
\end{tabular}

Tab.2: Microstructure and texture of rolled steels

\begin{tabular}{|c|c|c|c|}
\hline & & $\begin{array}{l}\text { LOW CARBON } \\
\text { STEEL }\end{array}$ & $\begin{array}{l}\text { ALLOYED STEELS } \\
\text { Fe16\%Cr, Fe3\%Si }\end{array}$ \\
\hline \multirow{2}{*}{ 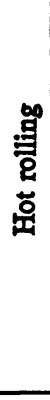 } & $\begin{array}{l}\text { Micro- } \\
\text { structure }\end{array}$ & $\begin{array}{l}100 \% \text { transfor- } \\
\text { mation } \gamma \rightarrow \alpha \\
\text { Small globular } \\
\text { grains }\end{array}$ & $\begin{array}{l}\text { Inhomogeneous through thickness: } \\
\text { Center: } \\
\text { Flat, strongly deformed grains, } \\
\text { not recrystallized } \\
\text { Surface: } \\
\text { Grains very large, esp. for Fe3\%Si }\end{array}$ \\
\hline & Texture & $\begin{array}{l}\text { Homogeneous } \\
\text { through } \\
\text { thickness; } \\
\text { nearly random }\end{array}$ & $\begin{array}{l}\text { Very inhomogeneous through thick- } \\
\text { ness } \\
\text { Center: } \\
\text { Strong rolling texture, } \alpha \text {-, } \gamma \text {-fibre } \\
\text { Surface: } \\
\text { Shear texture }\{011\}<100> \\
\approx\{112\}<111\rangle\end{array}$ \\
\hline \multirow[b]{2}{*}{ 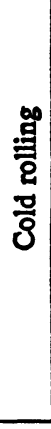 } & $\begin{array}{l}\text { Micro- } \\
\text { structure }\end{array}$ & \multicolumn{2}{|c|}{$\begin{array}{l}\text { Rolling degrees }<80 \% \text { : } \\
\text { Shear bands increasing with increasing amount of solute } \\
\text { carbon or grain size }\end{array}$} \\
\hline & Texture & $\begin{array}{l}\text { Increase of } \\
\alpha \text { - and } \gamma \text {-fibre } \\
\text { orientations: } \\
\text { Rolling degrees } \\
<75 \%: \\
\{112\}<110>, \alpha \\
\{11\}<112>, \gamma \\
\text { Rolling degrees } \\
>75 \%: \\
\{111\}<110>, \\
\alpha, \gamma\end{array}$ & $\begin{array}{l}\text { Inhomogeneous due to starting texture } \\
\text { Center: } \\
\text { Sharpening of hot rolling texture; } \\
\text { Increase of }\{112\}<110>, \alpha \\
\text { and of }\{111\}<110>, \alpha, \gamma \\
\text { Surface: } \\
\text { Increase of } \alpha \text { - and } \gamma \text { - fibre } \\
\text { orientations (see low carbon steels), } \\
\text { but much stronger }\{001\}<110>\end{array}$ \\
\hline \multirow{2}{*}{ 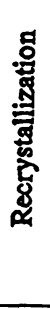 } & $\begin{array}{l}\text { Micro- } \\
\text { structure }\end{array}$ & \multicolumn{2}{|c|}{$\begin{array}{l}\text { Rolling degree <80\%: } \\
\text { First recrystallized grains in shear bands, } \\
\text { grains with strong work hardening ( }\{111\} \| N D) \\
\text { recrystallized first }\end{array}$} \\
\hline & Texture & \multicolumn{2}{|c|}{$\begin{array}{l}\text { Strong decrease of the } \alpha \text {-fibre orientations (without } \\
\{111\}<110>\text { ), } \\
\text { increasing density of Goss-orientation with increasing } \\
\text { amount of shear bands, } \\
\text { sharp rolling texture component }\{112\}<110>\text { leads to } \\
\text { a sharp recrystallization texture component }\{111\}<112>\end{array}$} \\
\hline
\end{tabular}


case of precipitated carbon (Fig.13b) the orientation density of Goss is strongly reduced. The reason seems to be that carbon in solution leads to more deformation inhomogeneities like shear bands $s^{4,5,3}$. In agreement also in additional investigations of interstitial free $\mathrm{Ti}$ bearing steels where the whole content of carbon is precipitated no Goss orientations could be observed. The same effect as well for shear band formation as for the high density of Goss may be reached by increasing initial grain size.

The alloyed steels show equivalent behavior. However the difference in texture and microstructure between surface and center layers of the sheets resulting from such differences in the hot bands and which are much less prononounced in low carbon steels. At the surface (Fig.14a) larger grains exist and therefore a strong $\eta$-fibre is formed by recrystallization. In the center layer the hotband microstructure consists of very thin elongated grains in which no shear band formation and thus no $\eta$-fiber occurs (Fig.14b). Here the strong rolling texture component $\{112\}<110\rangle$ effects a very strong recrystallization orientation $\{111\}<112>$ as already pointed out for the low carbon steel.

\section{REFERENCES}

1. M. Hölscher, dissertation, RWTH Aachen (1987).

2. H.J. Bunge, "Mathematische Methoden der Texturanalyse", AkademieVerlag, Berlin (1969).

3. C. Därmann, M. Hölscher, S. Mishra, K. Lũcke, Proceedings ICOTOM 7, Netherlands, 759 (1984).

4. C. Därmann, dissertation, RWTH Aachen (1983).

5. U.v. Schlippenbach, F. Emren, K. Lücke, Acta metall. 34, 1289 (1986).

6. G.I. Taylor, J. Inst. Met. 62, 307 (1938).

7. J.F.W. Bishop, R. Hill, Phil. Mag. 42, 414, 1298 (1951).

8. H. Honneff, Dissertation, RWTH Aachen (1980).

9. R. Fortunier, J. Hirsch, "Theoretical Techniques of Texture Analysis", ed. by H.J. Bunge, DGM-Verlag (1986).

10. I.L. Dillamore, H. Katoh, Met. Sci. 8, 21 (1974).

11. W.A. Backofen, B.B. Hundry, Trans. AIME, 197, 51 (1953).

12. G. Ibe, K. Lücke, Archiv Eisenhüttenwesen, 39, 693 (1968). 